\title{
COMUNICAÇÃO
}

\author{
[Communication]
}

\section{Características físicas do sêmen de galos de matriz pesada com 35 e 68 semanas de idade}

\author{
[Physical characteristics of semen from male broiler breeders]
}

J.M. Rocha Júnior ${ }^{1}$, N.C. Baião ${ }^{2}$

${ }^{1}$ Rua Irmã Eufêmia, 549/102

31255-810 - Belo Horizonte, MG

${ }^{2}$ Escola de Veterinária da UFMG

Recebido para publicação em 5 de setembro de 2000

Recebido, após modificações, em 4 de outubro de 2001

E-mail: karimau@ig.com.br

Os manuais de linhagem preconizam o final da vida produtiva tanto para machos como para fêmeas na $68^{a}$ semana de idade. A produção de sêmen de galos mostra que variáveis como volume, concentração, número total de espermatozóides por ejaculado e fertilidade mantêm-se satisfatórios até idade mais avançada (105 semanas), o que possibilita seu aproveitamento para a inseminação artificial por muitos ciclos de produção, adiando a reposição e conseqüentemente reduzindo os custos atribuídos ao alto preço dos reprodutores (Renden \& Pierson, 1982).

A produção de espermatozóides no galo atinge seu máximo entre 24 e 30 semanas de idade, mantêm-se elevada até 40-45 semanas de idade e decresce a partir dessa idade (Brillard \& McDaniel, 1985; Rosenstrauch et al., 1994). Lake (1989) e Sexton et al. (1989) relataram que a queda da fertilidade em galos a partir de $45^{\mathrm{a}}$ semana de idade foi acompanhada de redução do número de espermatozóides no ejaculado. Galos acima dessa idade apresentam libido diminuído e menor número de cópulas férteis (Wilson et al., 1979).

Hocking (1989) mostrou que a correlação entre volume de sêmen e idade é negativa. Para evitar queda de fertilidade atribuída à idade dos galos, em criações comerciais deve-se sempre substituir os velhos pelos novos. Tal procedimento proporciona bons resultados, embora onere a produção em função do preço elevado dos reprodutores (Branco, 1994).

Rosenstrauch et al. (1994), ao avaliarem a fertilidade de galos Cornish nas $32^{\mathrm{a}}, 48^{\mathrm{a}}, 70^{\mathrm{a}}$ e $110^{\mathrm{a}}$ semanas de idade encontraram, respectivamente, valores de 95, 90, 75 e 15\%. Observaram também redução na concentração espermática do sêmen. O epitélio seminífero dos galos foi examinado por microscopia eletrônica e foi detectada redução do diâmetro das células de Sertoli e elevação do número de espermatozóides nelas retidos com o aumento da idade, exceto em machos de fertilidade muito baixa. A fertilidade também foi avaliada pelo exame de ovos oriundos de galinhas inseminadas artificialmente e incubados por 10 dias, observando-se redução da fertilidade com o aumento da idade.

O objetivo deste trabalho foi o de avaliar a capacidade reprodutiva de galos com 68 e 35 semanas de idade pela análise de características físicas do sêmen e estabelecer a magnitude do efeito do tamanho do testículo, medidos a essas idades, sobre a qualidade do sêmen (motilidade, vigor e turbilhonamento). 
A análise da qualidade do sêmen foi realizada na Granja Rassi, localizada em Uberlândia - MG. O abate e a avaliação do peso dos testículos foram realizados na Universidade Federal de Uberlândia.

Os galos originaram-se de plantéis comerciais de matrizes pesadas da linhagem ISA-MPK da Granja Rassi. Foram utilizados cinco grupos de galos com 68 semanas de idade, retirados de cinco diferentes lotes de matrizes, e um grupo de 10 galos com 35 semanas de idade, originados de um único lote de matrizes. Cada grupo de 10 galos, representando um lote de matrizes foi alojado em um boxe com cama (cepilho de madeira) durante duas semanas. Nesse período foi feito o treinamento dos galos para a colheita do sêmen. Foram realizadas 14 colheitas no período de treinamento em galos individualmente identificados.

Durante a fase de treinamento para a colheita de sêmen os galos receberam o mesmo período de luminosidade diária que recebiam quando estavam nos galpões de origem (17 horas de luz e 7 horas de escuro). A ração oferecida durante esse período foi a mesma utilizada nos plantéis de origem, com o consumo fixado em $140 \mathrm{~g} / \mathrm{ave} / \mathrm{dia}$.

Após o treinamento, o sêmen colhido em seringa graduada por meio de massagem abdominal foi acondicionado em recipiente graduado, estéril e seco. Avaliaram-se o volume e a cor seguindo-se a retirada de uma gota, colocada em lâmina previamente aquecida a $38^{\circ} \mathrm{C}$ para observação da motilidade, do vigor e do turbilhonamento em microscópio óptico. Foram atribuídos valores de 0 a 5 para turbilhonamento e vigor (sendo zero para ausência total de turbilhonamento e vigor e 5 para a atividade máxima dessas características). A motilidade foi avaliada em percentagem.

Após as análises realizou-se o abate e a retirada dos testículos, identificados e pesados em balança de precisão.

Foram feitas análises de regressão da motilidade, vigor, turbilhonamento e volume em relação ao peso dos testículos, além do teste não paramétrico de Mann-Whitney para comparar os efeitos da idade (35 e 68 semanas) sobre essas características.

Na Tab. 1 são mostrados os resultados da análise descritiva das variáveis da qualidade do sêmen e peso dos testículos de galos com 35 e 68 semanas de idade.

Tabela 1. Análise descritiva de características do sêmen e peso dos testículos de galos segundo a idade

\begin{tabular}{lcl}
\hline Variável & 35 semanas & 68 semanas \\
\hline Turbilhonamento (0 a 5) & $3,9 \pm 1,4$ & $3,4 \pm 1,0$ \\
Motilidade \% & $84,0 \pm 20,7$ & $73,8 \pm 20,7$ \\
Vigor (0 a 5) & $4,2 \pm 1,1$ & $3,6 \pm 1,1$ \\
Peso dos testículos (g) & $39,30 \pm 8,07$ & $30,90 \pm 7,28$ \\
\hline
\end{tabular}

A média de peso dos testículos foi de $0,82 \%$ em relação ao peso vivo para os galos de 35 semanas, próximo ao valor de $0,76 \%$ encontrado por Brown \& McCartney (1986) em galos da linhagem Hubbard também no pico de produção (46 semanas de idade). Para os de 68 semanas de idade o valor médio foi de 0,62\%. Hocking (1989), ao utilizar galos da linhagem Cobb 500 com 60 semanas de idade, observou que os melhores índices de fertilidade foram apresentados por galos cujos testículos pesaram entre $21 \mathrm{e} 30 \mathrm{~g}$.

Para os galos de 35 semanas de idade a equação qualidade do sêmen em relação ao peso dos testículos foi $\mathrm{Y}=-5,14+0,120 \mathrm{X}$. A análise de regressão mostrou que $67,3 \%$ da variação na qualidade do sêmen dos galos de 35 semanas é explicada pelo peso dos testículos. Galos com testículos maiores apresentaram melhor qualidade de sêmen. Para os de 68 semanas, a equação foi estimada como $\mathrm{Y}=0,34-0,0110 \mathrm{X}$. A análise de regressão mostrou que o peso dos testículos não influiu na qualidade do sêmen nessa idade. 
Os resultados do teste não paramétrico indicaram que não houve diferença significativa nas características físicas espermáticas (motilidade, vigor e turbilhonamento) entre as idades de 35 e 68 semanas $(\mathrm{P}>0,05)$, mostrando que a queda de fertilidade em galos velhos deve ser causada por outros fatores.

Palavras-chave: Galo, qualidade do sêmen, peso dos testículos

\begin{abstract}
Sixty male broiler breeders (ISA-MPK breed) 50 at their final reproductive life (68 week-old), and 10 at the pick of production (35 week-old), from six different flocks (10 males/flock) were used to evaluate the effect of age on the motility, vigor and mass motility under normal management field conditions. A nonparametric test was applied and no differences were observed between ages for the analyzed traits. The regression analysis showed a significant effect of testicle weight on semen quality only for birds at 35 weeks of age.
\end{abstract}

Keywords: Male broiler breeder, semen quality, testicle weights

\title{
REFERÊNCIAS BIBLIOGRÁFICAS
}

BRANCO, J.A.D. Gerenciamento de produção. In: Manejo de matrizes. Campinas: Fundação APINCO de Ciência e Tecnologia. p.185-191, 1994.

BRILLARD, J.P., McDANIEL, G.R. The reliability and efficiency of various methods for estimating spermatozoa concentration. Poult. Sci., v.64, p.155-158, 1985.

BROWN, H.B., McCARTNEY, M.G. Restricted feeding and reproductive performance of individually caged broiler males. Poult. Sci., v.65, p.850-855, 1986.

HOCKING, P.M. Effect of dietary crude protein concentration on semen yield and quality in male broiler breeder fowls. Br. Poult. Sci., v.30, p.935-945, 1989.

LAKE, P. E. Recent progress in poultry reproduction. World's Poult. Sci. J., v.45, p.53-59, 1989.

RENDEN, J.A., PIERSON, M.L. Long term reproductive performance of broiler breeder males selected for semen production. Poult. Sci., v.61, p.1214-1217, 1982.

ROSENSTRAUCH, A., EGEN, A.A., FRIEDLÄNDER, M. Spermatozoa retention by Sertoli cells during the decline in fertility in aging roosters. Biol. Reprod., v.50, p.129-136, 1994.

SEXTON, K.J., RENDEN, J.A., MARPLE, D.N. et al. Effect of dietary energy on semen production, fertility, plasma testosterone, and carcass composition of broiler breeder males in cages. Poult. Sci., v.68, p.1688-1694, 1989.

WILSON, H.R. PIESCO, N.P. MILLER, E.R. et al. Prediction of the fertility potential of broiler breeder males. World's Poult. Sci. J., v.35, p.95-118, 1979. 